\title{
Eficiência e Seletividade dos Herbicidas Trifloxysulfuron- SOdIUM + AMETRYNe E HEXAZINONE + DiURON EM FUnÇÃo DA Tecnologia de Aplicação e do manejo mecânico da Palha de Cana-de-Açúcar na linha de Plantio ${ }^{1}$
}

\author{
Efficiency and Selectivity of Trifloxysulfuron Sodium + Ametryne and Hexazinone + Diuron \\ Herbicide as a Result of Application Technology and Mechanical Management of Sugarcane \\ Straw in the Crop Row
}
MACIEL, C.D.G. ${ }^{2}$, VELINI, E.D. ${ }^{3}$, CONSTANTIN, J. ${ }^{4}$, JARDIM, C.E. ${ }^{5}$, BERNARDO, R.S. ${ }^{5}$, FONSECA, P.P.M. ${ }^{6}$, BARELA, J.D. ${ }^{6}$ e OLIVEIRA, J.S. ${ }^{6}$

\begin{abstract}
RESUMO - Com objetivo de otimizar a utilização de trifloxysulfuron-sodium + ametryne e hexazinone + diuron em função da adoção de diferentes pontas de pulverização e manejo mecânico da palha de cana-de-açúcar na linha de plantio, dois experimentos foram conduzidos na Destilaria Parálcool S/A, localizada em Paraguaçu Paulista/SP. No experimento 1, 12 tratamentos foram estudados em esquema fatorial $2 \times 2 \times 3$, com quatro repetições, contrastando a presença e ausência de palha da cana na linha de plantio; dos herbicidas trifloxysulfuron sodium + ametryne $\left(37+1.463 \mathrm{~g}\right.$ i.a. ha ${ }^{-1}$ e $0,2 \% \mathrm{v} / \mathrm{v}$ de Aterbane $\left.{ }^{\circledR}\right)$ e hexazinone + diuron $\left(330+1.170 \mathrm{~g}\right.$ i.a. ha ${ }^{-1}$ e $0,2 \% \mathrm{v} / \mathrm{v}$ de Aterbane $\left.{ }^{\circledR}\right)$ e das pontas de pulverização XR11002-VS (128 L ha-1), AI11002-VS (200 L ha-1) e TF-VP5 (310 L ha-1). No experimento 2, a deposição da calda de pulverização nas plantas de cana-de-açúcar e Digitaria horizontalis, gerada pelas interações entre herbicidas e pontas, foi monitorada utilizandose solução traçadora constituída por corante FDC-1 + herbicida. Os resultados sugerem que a presença da palhada da cultura proporcionou controle excelente das espécies infestantes mesmo na ausência do tratamento herbicida. O controle químico de $D$. horizontalis (6 folhas até 1-2 perfilhos) e Brachiaria decumbens (2 a 6 folhas) apresentou-se eficiente (> $91 \%$ ) nas linhas sem palha a partir dos 14 DAA (dias após aplicação) para os herbicidas e pontas de pulverização estudados. D. horizontalis foi mais rapidamente controlada aos 7 DAA pelo trifloxysulfuron-sodium + ametryne com a ponta AI11002-VS. Houve toxicidade até os $21 \mathrm{DAA}$, sendo esta mais intensa para os tratamentos com hexazinone + diuron associado com as pontas AI11002-VS e TF-VP5, em decorrência da maior deposição do herbicida nas folhas da cultura.
\end{abstract}

Palavras-chave: Saccharum spp., manejo da palha, herbicida, pontas de pulverização.

\begin{abstract}
Aiming to optimize the use of trifloxysulfuron sodium + ametryne and hexazinone + diuron following adoption of different spray nozzles and sugarcane straw management in the crop row, two experiments were conducted at Parálcool Sugar Mill S/A in Paraguaçu Paulista/SP. In Experiment 1, twelve treatments arranged in a $2 \times 2 \times 3$ factorial scheme were performed, with four replications to evaluate the presence and absence of sugarcane straw in the crop row, and use of the herbicides trifloxysulfuron sodium + ametryne $\left(37+1463 \mathrm{~g} \mathrm{ha}^{-1}\right.$ and $0.2 \% \mathrm{v} / \mathrm{v}$ of Aterbane $\left.{ }^{\circledR}\right)$ and diuron thexazinone $\left(330+1170 \mathrm{~g} \mathrm{ha}^{-1}\right.$ and $0.2 \% \mathrm{v} / \mathrm{v}$ of Aterbane $\left.{ }^{\circledR}\right)$ and spray nozzles XR11002-VS (128 $\left.\mathrm{L} \mathrm{ha}^{-1}\right)$, AI1 1002-VS (200 L ha-1) and TF-VP5 (310 L ha 1). In Experiment 2, The application of spraying solution on sugarcane and Digitaria horizontalis plants, generated by the combination of the herbicides and the spray nozzles, was monitored by using a tracer solution constituted by coloring FDC-1 + herbicide. The results suggest that the
\end{abstract}

Recebido para publicação em 3.6.2007 e na forma revisada em 6.2.2008

Prof., Dr., Dep. de Ciências Biológicas e Fitossanitárias, Escola Superior de Agronomia de Paraguaçu Paulista - FUNGE/ ESAPP, Paraguaçu Paulista-SP, Caixa Postal 88, 19700-000, <macielconsultoria@hotmail.com>; ${ }^{3}$ Prof. Assistente Dr., do Dep. de Produção Vegetal, UNESP/FCA, Botucatu-SP; ${ }^{4}$ Prof. Adjunto, Dr., Dep. de Agronomia, Universidade Estadual de Maringá UEM, Maringá-PR; ${ }^{5}$ Alunos do curso de Agronomia da FUNGE/ESAPP - Paraguaçu Paulista-SP; ${ }^{6}$ Funcionários da Empresa Destilaria Parálcool S/A. 
crop straw provided excellent control of the infesting species, even in the absence of herbicide treatment. For D. horizontalis (6 leaves to 1-2 tillers) and Brachiaria decumbens (2 to 6 leaves) chemical control was efficient (>91\%) in the rows without straw, after 14 DAA (days after application) for the herbicides and spray nozzles studied. D.horizontalis was more quickly controlled at 7 DAA by using trifloxysulfuron sodium + ametryne with AI1 1002-VS spray nozzle. Crop injury was observed up to 21 DAA, becoming more intense when diuron + hexazinone combinedwith AI1 1002-VS and TF-VP5 nozzle were used, due to higher herbicide deposition on the crop leaves.

Keywords: $\quad$ sugarcane, mulch management, herbicide, spray nozzles.

\section{INTRODUÇÃO}

A cultura da cana-de-açúcar (Saccharum spp.) ocupa posição de destaque no cenário agrícola nacional, colaborando com o suprimento energético do País em matériaprima para obtenção de álcool e como fonte de divisas na produção de açúcar exportado para vários países (Constantin, 1996). Atualmente, o Brasil é o maior produtor mundial, destacando-se o Estado de São Paulo, responsável por 53,3\% da produção nacional (FNP, 2008).

A competição por recursos do meio gerada pelas plantas daninhas acarreta redução significativa no rendimento na cultura da canade-açúcar (Rolim \& Christoffoleti, 1982; Lorenzi et al., 1988; Graciano, 1989; Constantin et al., 1993; Coleti et al., 1997; Kuva et al., 2000, 2001, 2003), assim como proporciona outros aspectos negativos, como decréscimo da longevidade do canavial, redução da qualidade industrial da matéria-prima e dificuldade nas operações de colheita e transporte (Pitelli, 1985; Procópio et al., 2003). Dessa forma, é evidente a necessidade de estratégias eficientes no controle das comunidades infestantes para a cultura em questão.

No contexto de manejo de plantas daninhas, a aplicação de herbicidas em pós-emergência é uma prática bastante comum nos diferentes sistemas produtivos de cana-deaçúcar. Mais recentemente, em sistemas de cana crua, em que a quantidade de palha depositada sobre a superficie do solo pode superar 20 t ha $^{-1}$, essa modalidade de aplicação tem sido predominante em razão da dificuldade de utilização de herbicidas de pré-emergência e da necessidade de adaptação de diversas tecnologias (Velini \& Negrisoli, 2000).

Ao contrário do benefício gerado pela preservação da palha em relação à germinação de plantas daninhas, devido às alterações fisicas e químicas nas entrelinhas e linhas das culturas (Taylorson \& Borthwick, 1969; Fener, 1980; Lorenzi, 1993; Zimdahl, 1993; Martins et al., 1999), algumas situações têm sido estudadas, em que a remoção mecânica da palhada é efetuada somente sobre a linha de plantio da cana-de-açúcar. Nesse sentido, a retirada da palha localizada sobre a linha de plantio visa melhorar a brotação e o crescimento das diferentes variedades em condição de cana-soca, assim como, provavelmente, otimizar o uso de adubos nitrogenados e reduzir o ataque de pragas.

No entanto, a retirada da palha somente sobre a linha de plantio condicionará a necessidade do controle efetivo e localizado da infestação apenas na linha de plantio. Essa situação, provavelmente, permite vantagem no manejo da infestação para a maioria dos casos em condição de cana crua, desde que haja interação positiva entre herbicidas de pós-emergência e a tecnologia da ponta de pulverização, objetivando minimizar o efeito "guarda-chuva" em condições de perfilhamento mais vigoroso.

Dessa forma, o presente trabalho teve por objetivo otimizar a eficiência e seletividade dos herbicidas trifloxysulfuron-sodium + ametryne (Krismat ${ }^{\circledR}$ ) e hexazinone + diuron $\left(\right.$ Velpar $\mathrm{K}^{\circledR}$ ), em função da adoção de diferentes pontas de pulverização, associadas ao manejo mecânico da palha de cana-de-açúcar na linha de plantio.

\section{MATERIAL E MÉTODOS}

O trabalho foi constituido de dois experimentos conduzidos a campo em área pertencente à Destilaria Parálcool S/A, localizada no município de Paraguaçu Paulista/SP, utilizando a variedade SP 80 1842, com espaçamento 
entre linhas de $1,4 \mathrm{~m}$ e em condição de soca de terceiro ano.

O solo da área experimental foi classificado como Latossolo distrófico de textura arenosa, sendo constituído por $86,4 \%$ de areia total, $7,4 \%$ de argila e $6,2 \%$ de silte, com as seguintes características químicas: $\mathrm{pH}\left(\mathrm{CaCl}_{2}\right)$ $=5,1 ; \mathrm{MO}=12,0 \mathrm{~g} \mathrm{dm}^{-3} ; \mathrm{P}=6,0 \mathrm{mg} \mathrm{dm}^{-3} ; \mathrm{H}^{+}+\mathrm{Al}^{3+}$ $=10,0 \mathrm{cmol}_{\mathrm{c}} \mathrm{dm}^{-3} ; \mathrm{K}^{+}=1,9 \mathrm{cmol}_{\mathrm{c}} \mathrm{dm}^{-3} ; \mathrm{Ca}^{++}=$ $14,0 \mathrm{cmol}_{c} \mathrm{dm}^{-3} ; \mathrm{Mg}^{++}=5,0 \mathrm{cmol}_{c} \mathrm{dm}^{-3} ; \mathrm{SB}=$ 20,$0 ; \mathrm{CTC}=35,0 ;$ e V\% $=57$.

No primeiro experimento, 12 tratamentos foram estudados em esquema fatorial $2 \times 2 \times 3$, com quatro repetições, apresentando como variáveis a presença ou ausência de palhada da cana na linha de plantio, os herbicidas trifloxysulfuron-sodium + ametryne $\left(37+1.463\right.$ g i.a. ha ${ }^{-1}$ e $0,2 \%$ dev/v de Aterbane $\left.{ }^{\circledR}\right)$ e hexazinone + diuron $\left(330+1.170\right.$ g i.a. ha ${ }^{-1}$ e $0,2 \%$ de $\mathrm{v} / \mathrm{v}$ de Aterbane ${ }^{\circledR}$ ) e as pontas de pulverização XR11002-VS, AI11002-VS e TFVP5. A retirada da palha na linha de plantio, representada por $9.150 \mathrm{~kg}$ de matéria seca por hectare, foi efetuada logo no início da emissão dos primeiros perfilhos da cultura, rastelandose a palhada de aproximadamente $50,0 \mathrm{~cm}$ da largura total da linha para a entrelinha, simulando a operação mecanizada de manejo.

O delineamento experimental utilizado foi o de blocos casualizados, com quatro repetições, sendo a condição de presença e ausência de palhada na linha de plantio alocada em parcelas principais de $4,2 \times 35,0 \mathrm{~m}\left(147,0 \mathrm{~m}^{2}\right)$, onde as combinações para cada herbicida estudado e pontas de pulverização e uma testemunha, em subparcelas constituídas por quatro linhas da cultura e dimensão de 4,2 x 5,0 m $\left(21,0 \mathrm{~m}^{2}\right)$. Nessa etapa, foram avaliados a toxicidade à cultura da cana-de-açúcar e o controle da infestação constituída por Digitaria horizontalis e Brachiaria decumbens aos 7, 14, 21, 28 e 63 dias após a aplicação (DAA). Além disso, também foram analisados o controle geral da infestação, representado por todas as espécies de plantas daninhas, e, para a cultura da cana-de-açúcar, as variáveis altura da distância entre o solo até a região auricular da folha +1 (Dillewijn, 1952), número de perfilhos por metro linear e diâmetro mediano de colmos, todos aos 90 DAA. Para o controle da infestação, notas visuais foram atribuídas aos efeitos dos tratamentos, em que $0 \%$ correspondeu à "ausência de controle" e 100\% ao "controle total" (SBCPD, 1995). De forma semelhante ao controle da infestação, a fitotoxicidade na cultura também foi avaliada através de escala percentual de notas da EWRC (1964), em que 0\% correspondeu à ausência de injúrias e $100 \%$ à morte das plantas.

No segundo experimento, as deposições da calda de pulverização nas folhas de cana-deaçúcar e capim-colchão, resultantes de todos os tratamentos estudados no primeiro experimento, foram monitoradas com auxílio do corante FDC-1. Para isso, soluções traçantes de FDC-1, na concentração de 3.000 ppm, foram pulverizadas em associação aos herbicidas estudados. As repetições foram constituídas de 20 perfilhos de cana com cinco a sete folhas, 30 plântulas de capim-colchão com três a cinco folhas e cinco lâminas de vidro com área de $19,76 \mathrm{~cm}^{2}$, posicionadas nas entrelinhas da cultura. As folhas e lâminas de vidro serviram como aparato, em que o corante depositado foi posteriormente recuperado e quantificado, através da lavagem dos alvos, com auxílio de sacos plásticos e volume de água destilada previamente estipulado.

A determinação da quantidade depositada do corante FDC-1, por meio das soluções recuperadas nos alvos, foi feita utilizando-se um espectrofotômetro nos laboratórios do NuPAM/ UNESP/FCA, cujos resultados da leitura em absorbância no comprimento de onda de $630 \mathrm{~nm}$ proporcionaram a definição da sua concentração ( $\left.\mathrm{mg} \mathrm{L}^{-1}\right)$, de acordo com os coeficientes angulares das curvas-padrão $\left(R^{2} \geq 0,99998\right)$. Os valores de depósito foram posteriormente transformados em $\mu \mathrm{L}$ planta $^{-1}$ e $\mu \mathrm{L} \mathrm{cm}^{-2}$, conforme metodologia descrita por Palladini (2000) e Souza (2002).

Nos dois experimentos, as aplicações foram realizadas em pós-emergência, nos dias $26 / 9 / 2003$ e $27 / 9 / 2003$. O estádio de desenvolvimento de $D$. horizontalis variou de 6 folhas a 1-2 perfilhos (plantas pequenas) até 6 a 10 perfilhos (plantas grandes). Para $B$. decumbens, entre 2 e 6 folhas (plantas pequenas) até 6 a 8 perfilhos (plantas grandes). Essas plantas foram encontradas apenas na região da linha de plantio, onde a palhada havia sido manejada. A cultura da cana-de-açúcar apresentava-se em perfilhamento, com 5 a 
7 folhas e altura de aproximadamente $50 \mathrm{~cm}$. Na aplicação, o número médio de infestantes nas linhas das testemunhas onde a palha foi manejada foi de, respectivamente, 14 e 9 plantas de $D$. horizontalis e $B$. decumbens por metro quadrado.

As pulverizações dos herbicidas nos experimentos foram realizadas no final da tarde, utilizando-se um pulverizador costal de $\mathrm{CO}_{2}$, mantido em pressão constante e com os seguintes consumos de calda e pontas de pulverização: $128 \mathrm{~L} \mathrm{ha}^{-1}$ (XR11002-VS), $200 \mathrm{~L} \mathrm{ha}^{-1}$ (AI11002-VS) e $310 \mathrm{~L} \mathrm{ha}^{-1}$ (TF-VP5). O solo apresentava-se úmido e as condições climáticas registradas no momento das aplicações foram, respectivamente, para o primeiro e segundo experimentos: temperatura do ar de 24 e $28^{\circ} \mathrm{C}$, umidade relativa do ar de 66 e $60 \%$ e ventos de 4,0 e 5,8 $\mathrm{km} \mathrm{h}^{-1}$. As precipitações e temperaturas médias diárias registradas no período compreendido entre setembro/2003 e dezembro/2003 encontram-se na Figura 1.

No primeiro experimento, os resultados foram submetidos à análise de variância pelo teste $\mathrm{F}$ e as suas médias comparadas pelo teste " $t$ " a $5 \%$ de probabilidade. No segundo, os dados referentes aos depósitos foram ajustados pelo modelo de Gompertz $\left(\mathrm{F}=\mathrm{e}^{\wedge}\left(\mathrm{a}-\mathrm{e}^{\wedge}(-\mathrm{b} \mathrm{c}\right.\right.$ * $\mathrm{X})$ )), sendo representadas as freqüências acumuladas da deposição da calda pulverizada, em porcentagem. Adotou-se o valor de 4,60517 para o parâmetro "a" do modelo, o qual representa a assintota máxima da curva, em que " $\mathrm{e}$ " = 100 , conforme modelo ajustado por Velini (1995).

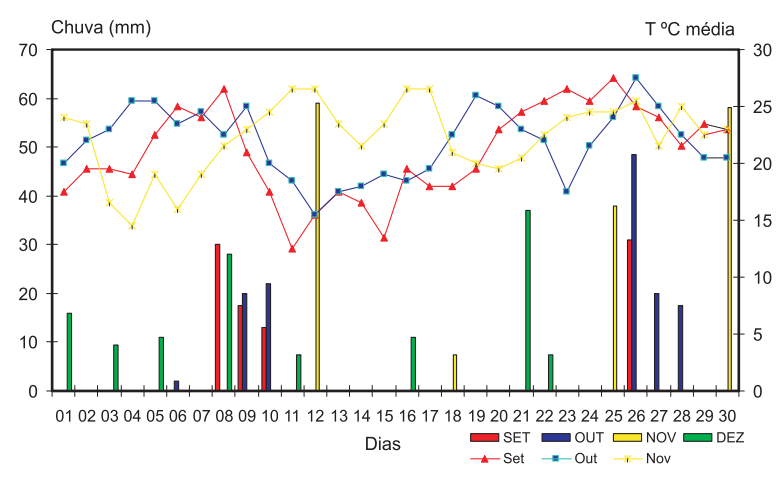

Figura 1 - Precipitações (mm) e temperaturas $\left({ }^{\circ} \mathrm{C}\right)$ médias diárias no período referente a setembro/2003 e dezembro/ 2003. Paraguaçu Paulista-SP, 2004.
Os valores de média, moda e mediana também foram estabelecidos no trabalho. A precisão do ajuste dos dados do modelo de Gompertz foi avaliada pelos coeficientes de determinação $\left(\mathrm{R}^{2}\right)$ e pelas somas dos quadrados de resíduos das equações.

\section{RESULTADOS E DISCUSSÃO}

A comunidade infestante, constituída pelas gramineas $D$. horizontalis e $B$. decumbens, foi eficientemente controlada pela presença da palhada sobre a superficie do solo, ou seja, na ausência do manejo da palha sobre a linha de plantio. Dessa forma, no momento da aplicação dos tratamentos químicos não houve a presença de infestação para a condição de cana crua sem manejo da palha na linha de plantio, mas ainda assim foram avaliados os efeitos de toxicidade sobre a cultura da canade-açúcar.

Para $D$. horizontalis com 6 folhas até 1 a 2 perfilhos (plantas pequenas), apenas o herbicida trifloxysulfuron-sodium + ametryne $\left(37+1.463\right.$ g i.a. ha ${ }^{-1}$ e $0,2 \%$ de v/v de Aterbane $\left.{ }^{\circledR}\right)$ aplicado com a ponta de pulverização AI 1002VS apresentou controle satisfatório aos 7 DAA, embora não tenham sido constatadas diferenças significativas em relação às pontas XR11002-VS e TF-VP5 (Tabela 1). Nessa avaliação, o herbicida hexazinone + diuron $\left(330+1.170\right.$ g i.a. ha ${ }^{-1}$ e $0,2 \%$ de v/v de Aterbane $^{\circledR}$ ) não atingiu o controle minimo aceitável (> 80,0\%) de $D$. horizontalis, sendo seu desempenho inferior a $71,0 \%$, para todas as pontas avaliadas. Aos 14 DAA, os tratamentos trifloxysulfuron-sodium + ametryne com os três tipos de pontas de pulverização apresentaram controle eficiente $(>90,0 \%)$ de $D$. horizontalis, não diferindo significativamente entre si. Entretanto, para hexazinone + diuron o controle de $D$. horizontalis foi apenas satisfatório para as três pontas de pulverização, apesar de não ter ocorrido interação significativa entre as variáveis herbicida e pontas de pulverização aos 14 DAA. Dessa forma, a mistura trifloxysulfuron-sodium + ametryne exerceu controle mais eficiente de $D$. horizontalis, em relação a hexazinone + diuron, nas aplicações desenvolvidas com a ponta modelo AI $11002-V S$, apenas aos 7 DAA. A partir dos 21 DAA, os herbicidas estudados nas diferentes modalidades de aplicação apresentaram controle eficiente de 
Tabela 1 - Controle (\%) de Digitaria horizontalis em estádio de 6 folhas até 1-2 perfilhos aos 7, 14, 21, 28 e 63 dias após a aplicação de trifloxysulfuron-sodium + ametryne $\left(\right.$ Krismat $\left.^{\circledR}\right)$ e hexazinone + diuron $\left(\right.$ Velpar $\left.\mathrm{K}^{\circledR}\right)$ na cultura da cana-de-açúcar

\begin{tabular}{|c|c|c|c|c|c|c|c|c|c|c|}
\hline \multirow{2}{*}{$\begin{array}{c}\text { Pontas de } \\
\text { pulverização }\end{array}$} & \multicolumn{2}{|c|}{$7 \mathrm{DAA}^{1 /}$} & \multicolumn{2}{|c|}{14 DAA } & \multicolumn{2}{|c|}{$21 \mathrm{DAA}$} & \multicolumn{2}{|c|}{28 DAA } & \multicolumn{2}{|c|}{63 DAA } \\
\hline & Krismat $^{\circledR}$ & ${\text { Velpar } \mathrm{K}^{\circledR}}^{\circledR}$ & Krismat $^{(\mathbb{Q}}$ & ${\text { Velpar } \mathrm{K}^{\circledR}}^{\circledR}$ & Krismat $^{(\mathbb{B}}$ & 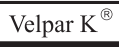 & Krismat $^{(2)}$ & Velpar $\mathrm{K}^{\circledR}$ & Krismat $^{(8)}$ & Velpar K $^{(\circledast)}$ \\
\hline $\begin{array}{l}\text { XR11002-VS } \\
\left(128 \mathrm{~L} \mathrm{ha}^{-1}\right)\end{array}$ & 69,5 a A & 61,2 a A & $91,0 \mathrm{a}$ & $85,0 \mathrm{a}$ & $92,5 \mathrm{a}$ & 95,5 a & 94,7 b B & 97,5 a A & $99,5 \mathrm{a}$ & 98,7 a \\
\hline $\begin{array}{l}\text { AI11002-VS } \\
\left(200 \mathrm{~L} \mathrm{ha}^{-1}\right)\end{array}$ & 80,0 a A & 65,0 a B & $92,0 \mathrm{a}$ & 82,7 a & 95,5 a & $88,0 \mathrm{a}$ & 93,7 b B & 99,0 a A & 99,0 a & $99,0 \mathrm{a}$ \\
\hline $\begin{array}{l}\text { TF-VP5 } \\
\left(310 \mathrm{~L} \mathrm{ha}^{-1}\right) \\
\end{array}$ & 78,2 a A & 70,7 a A & $91,2 \mathrm{a}$ & $88,0 \mathrm{a}$ & $97,0 \mathrm{a}$ & 95,2 a & 99,2 a A & $100,0 \mathrm{a} \mathrm{A}$ & $100,0 \mathrm{a}$ & $99,0 \mathrm{a}$ \\
\hline Testemunha & $0,0 \mathrm{~b} \mathrm{~A}$ & $0,0 \mathrm{~b} \mathrm{~A}$ & $0,0 \mathrm{~b}$ & $0,0 \mathrm{~b}$ & $0,0 \mathrm{~b}$ & $0,0 \mathrm{~b}$ & $0,0 \mathrm{~b} \mathrm{~A}$ & $00,0 \mathrm{~b} \mathrm{~A}$ & $00,0 \mathrm{~b}$ & $0,0 \mathrm{~b}$ \\
\hline Herbicidas $(\mathrm{H})$ & \multicolumn{2}{|c|}{$4,85^{*}$} & \multicolumn{2}{|c|}{$3,72^{\mathrm{NS}}$} & \multicolumn{2}{|c|}{$3,45^{\mathrm{NS}}$} & \multicolumn{2}{|c|}{$14,09 * *$} & \multicolumn{2}{|c|}{$0,41^{\mathrm{NS}}$} \\
\hline Pontas (P) & \multicolumn{2}{|c|}{$104,27^{* *}$} & \multicolumn{2}{|c|}{$381,33^{* *}$} & \multicolumn{2}{|c|}{$991,98^{* *}$} & \multicolumn{2}{|c|}{$6608,54 * *$} & \multicolumn{2}{|c|}{$16359,89^{* *}$} \\
\hline $\mathrm{H} \times \mathrm{P}$ & \multicolumn{2}{|c|}{$0,77^{\mathrm{NS}}$} & \multicolumn{2}{|c|}{$0,81^{\mathrm{NS}}$} & \multicolumn{2}{|c|}{$1,22^{\mathrm{NS}}$} & \multicolumn{2}{|c|}{$3,91 *$} & \multicolumn{2}{|c|}{$0,34^{\mathrm{NS}}$} \\
\hline CV (\%) & \multicolumn{2}{|c|}{18,58} & \multicolumn{2}{|c|}{9,66} & \multicolumn{2}{|c|}{5,99} & \multicolumn{2}{|c|}{2,32} & \multicolumn{2}{|c|}{1,47} \\
\hline DMS (5\%) & \multicolumn{2}{|c|}{14,51} & \multicolumn{2}{|c|}{9,43} & \multicolumn{2}{|c|}{6,16} & \multicolumn{2}{|c|}{2,49} & \multicolumn{2}{|c|}{1,62} \\
\hline
\end{tabular}

1/ Dias após aplicação.

Médias seguidas de mesma letra, minúscula na coluna e maiúscula na linha, não diferem estatisticamente entre si pelo teste $t$ ( $\mathrm{p}<0,05$ ).

$* *=$ valor significativo pelo teste $\mathrm{F}$ a $\mathrm{p}<0,01 ; *=$ valor significativo pelo teste $\mathrm{F} \mathrm{a} \mathrm{p}<0,05$ ); Ns $=$ não-significativo.

D. horizontalis (plantas pequenas), atingindo niveis excelentes e superiores a 98,7\% aos 63 DAA (Tabela 1). Resultados de controle de D. horizontalis em estádio inicial de desenvolvimento com trifloxysulfuron-sodium + ametrine e hexazinone + diuron, semelhantes aos do presente trabalho, foram constatados por Soares et al. (2000) e Barros \& Leonel (2001).

Os herbicidas trifloxysulfuron-sodium + ametrine e hexazinone + diuron não controlaram satisfatoriamente $D$. horizontalis em estádio de 6 a 10 perfilhos (plantas grandes) até os 14 DAA (Tabela 2), apesar de ter ocorrido interação entre herbicida e ponta de pulverização, com destaque para a ponta TF-VP5. Aos 21 e 28 DAA, somente as combinações dos herbicidas trifloxysulfuron-sodium + ametryne e hexazinone + diuron com a ponta TF-VP5 e hexazinone + diuron com a ponta AI11002-VS controlaram satisfatoriamente $D$. horizontalis (plantas grandes) em niveis de 82,0, 85,0 e $80,0 \%$, respectivamente, não diferindo significativamente entre si. Entretanto, aos 63 DAA, algumas plantas que escaparam ao controle ou ainda estavam sob o efeito supressivo dos herbicidas começaram a desenvolver rebrotações. Assim, apenas o hexazinone + diuron, em que foi utilizada a ponta TF-VP5, apresentou controle satisfatório $(84,0 \%)$, diferindo significativamente do trifloxysulfuron-sodium
+ ametryne, em que foi utilizada a ponta TFVP5 (70,0\%), assim como dos demais tratamentos.

Os herbicidas trifloxysulfuron-sodium + ametryne $\left(37+1.463\right.$ g i.a. ha ha $^{-1}$ e, $2 \%$ de v/v de Aterbane $\left.{ }^{\circledR}\right)$ e hexazinone + diuron $(330+$ 1.170 g i.a. ha ${ }^{-1}$ e $0,2 \%$ de v/v de Aterbane $\left.{ }^{\circledR}\right)$ controlaram eficientemente (> 92,75\%) $B$. decumbens com 2 a 6 folhas (plantas pequenas) em todas as modalidades de pulverização estudadas (Tabela 3). A partir dos 21 DAA, o controle estabilizou-se em nivel excelente (> $98,0 \%)$ e persistiu até o início do fechamento da cultura (63 DAA), não havendo diferenças significativas entre herbicidas e modalidades de pulverização.

De forma semelhante aos resultados obtidos para $D$. horizontalis (plantas grandes), apenas os herbicidas trifloxysulfuron-sodium + ametryne e hexazinone + diuron combinados à ponta TF-VP5 controlam satisfatoriamente $B$. decumbens com 6 a 8 perfilhos (plantas grandes) aos 7 DAA (Tabela 4), alcançando níveis de 86,2 e $82,5 \%$, respectivamente. As pontas AI 11002-VS e XR11002-VS combinadas aos herbicidas estudados proporcionaram desempenho inferior ao da ponta TF-VP5, não sendo significativamente diferentes entre si. A partir dos 14 DAA, os herbicidas trifloxysulfuron-sodium + ametryne e hexazinone + diuron, 
Tabela 2 - Controle (\%) de Digitaria horizontalis em estádio de 6 a 10 perfilhos aos 7, 14, 21, 28 e 63 dias após a aplicação de trifloxysulfuron-sodium + ametryne $\left(\right.$ Krismat $\left.^{\circledR}\right)$ e hexazinone + diuron $\left(\right.$ Velpar $\left.\mathrm{K}^{\circledR}\right)$ na cultura da cana-de-açúcar

\begin{tabular}{|c|c|c|c|c|c|c|c|c|c|c|}
\hline \multirow{2}{*}{$\begin{array}{c}\text { Pontas de } \\
\text { pulverização }\end{array}$} & \multicolumn{2}{|c|}{$7 \mathrm{DAA}^{1 /}$} & \multicolumn{2}{|c|}{14 DAA } & \multicolumn{2}{|c|}{$21 \mathrm{DAA}$} & \multicolumn{2}{|c|}{$28 \mathrm{DAA}$} & \multicolumn{2}{|c|}{63 DAA } \\
\hline & Krismat $^{\circledR}$ & Velpar $\mathrm{K}^{\circledR}$ & Krismat $^{\left({ }^{\circledR}\right.}$ & Velpar $\mathrm{K}^{\circledR}$ & Krismat $^{\circledR}$ & Velpar $\mathrm{K}^{\circledR}$ & Krismat ${ }^{\circledR}$ & Velpar $\mathrm{K}^{\circledR}$ & Krismat $^{\circledR}$ & Velpar $\mathrm{K}^{\circledR}$ \\
\hline $\begin{array}{l}\text { XR11002-VS } \\
\left(128 \mathrm{~L} \mathrm{ha}^{-1}\right)\end{array}$ & $26,2 \mathrm{c} \mathrm{A}$ & 32,5 b A & 30,0 c B & $42,5 \mathrm{~b} \mathrm{~A}$ & $17,5 \mathrm{c} \mathrm{B}$ & $38,7 \mathrm{~b} \mathrm{~A}$ & $23,7 \mathrm{c} \mathrm{B}$ & $40,0 \mathrm{~b} \mathrm{~A}$ & $15,0 \mathrm{~b} \mathrm{~B}$ & $22,5 \mathrm{c} \mathrm{A}$ \\
\hline $\begin{array}{l}\text { AI11002-VS } \\
\left(200 \mathrm{~L} \mathrm{ha}^{-1}\right)\end{array}$ & $53,7 \mathrm{~b} \mathrm{~A}$ & $36,2 \mathrm{ab} B$ & 46,2 b B & 70,0 a A & $38,7 \mathrm{~b} \mathrm{~B}$ & 81,2 a A & 40,0 b B & 80,0 a A & $25,0 \mathrm{~b} \mathrm{~B}$ & $71,2 \mathrm{~b} \mathrm{~A}$ \\
\hline $\begin{array}{l}\text { TF-VP5 } \\
\left(310 \mathrm{~L} \mathrm{ha}^{-1}\right)\end{array}$ & 68,7 a A & 50,0 a $\mathrm{B}$ & 78,7 a A & $78,0 \mathrm{a} A$ & 83,7 a A & 87,7 a A & 82,0 a A & 85,0 a A & 70,0 a B & 84,0 a A \\
\hline Testemunha & $0,0 \mathrm{dA}$ & $0,0 \mathrm{c} \mathrm{A}$ & $0,0 \mathrm{dA}$ & $0,0 \mathrm{c} \mathrm{A}$ & $0,0 \mathrm{dA}$ & $0,0 \mathrm{c} \mathrm{A}$ & $0,0 \mathrm{dA}$ & $0,0 \mathrm{cA}$ & $0,0 \mathrm{dA}$ & $0,0 \mathrm{dA}$ \\
\hline Herbicidas $(\mathrm{H})$ & \multicolumn{2}{|c|}{$4,75^{*}$} & \multicolumn{2}{|c|}{$9,59 * *$} & \multicolumn{2}{|c|}{$40,82 * *$} & \multicolumn{2}{|c|}{$30,58^{* *}$} & \multicolumn{2}{|c|}{$56,48^{* *}$} \\
\hline Pontas $(\mathrm{P})$ & \multicolumn{2}{|c|}{$52,57 * *$} & \multicolumn{2}{|c|}{$137,05^{* *}$} & \multicolumn{2}{|c|}{$199,53 * *$} & \multicolumn{2}{|c|}{$185,18^{* *}$} & \multicolumn{2}{|c|}{$222,61 * *$} \\
\hline $\mathrm{H} \times \mathrm{P}$ & \multicolumn{2}{|c|}{$3,19 *$} & \multicolumn{2}{|c|}{$4,12^{*}$} & \multicolumn{2}{|c|}{$15,30^{* *}$} & \multicolumn{2}{|c|}{$11,90 * *$} & \multicolumn{2}{|c|}{$20,06^{* *}$} \\
\hline $\mathrm{CV}(\%)$ & \multicolumn{2}{|c|}{29,68} & \multicolumn{2}{|c|}{18,76} & \multicolumn{2}{|c|}{17,20} & \multicolumn{2}{|c|}{17,11} & \multicolumn{2}{|c|}{17,82} \\
\hline DMS (5\%) & \multicolumn{2}{|c|}{14,59} & \multicolumn{2}{|c|}{11,92} & \multicolumn{2}{|c|}{10,98} & \multicolumn{2}{|c|}{11,05} & \multicolumn{2}{|c|}{9,44} \\
\hline
\end{tabular}

1/ Dias após aplicação.

Médias seguidas de mesma letra, minúscula na coluna e maiúscula na linha, não diferem estatisticamente entre si pelo teste $t$ ( $\mathrm{p}<0,05$ ).

$* *$ = valor significativo pelo teste $\mathrm{F}$ a $\mathrm{p}<0,01 ; *=$ valor significativo pelo teste $\mathrm{F}$ a $\mathrm{p}<0,05$; Ns $=$ não-significativo.

Tabela 3 - Controle (\%) de Brachiaria decumbens em estádio de 2 a 6 folhas aos 7, 14, 21, 28 e 63 dias após a aplicação de trifloxysulfuron-sodium + ametryne $\left(\right.$ Krismat $\left.^{\circledR}\right)$ e hexazinone + diuron $\left(\right.$ Velpar $\left.\mathrm{K}^{\circledR}\right)$ na cultura da cana-de-açúcar

\begin{tabular}{|c|c|c|c|c|c|c|c|c|c|c|}
\hline \multirow{2}{*}{$\begin{array}{c}\text { Pontas de } \\
\text { pulverização }\end{array}$} & \multicolumn{2}{|c|}{$7 \mathrm{DAA}^{\frac{1}{}}$} & \multicolumn{2}{|c|}{14 DAA } & \multicolumn{2}{|c|}{$21 \mathrm{DAA}$} & \multicolumn{2}{|c|}{$28 \mathrm{DAA}$} & \multicolumn{2}{|c|}{63 DAA } \\
\hline & Krismat $^{(\otimes)}$ & Velpar $\mathrm{K}^{\circledast}$ & Krismat $^{(\circledast)}$ & Velpar $\mathrm{K}^{\circledR}$ & Krismat $^{\otimes}$ & Velpar $\mathrm{K}^{\circledast}$ & Krismat $^{(\circledast)}$ & Velpar $\mathrm{K}^{\circledast}$ & Krismat $^{\circledR}$ & Velpar $\mathrm{K}^{\circledR}$ \\
\hline $\begin{array}{l}\text { XR11002-VS } \\
\left(128 \mathrm{~L} \mathrm{ha}^{-1}\right)\end{array}$ & 93,2 a & $92,7 \mathrm{a}$ & 97,2 a & $96,5 \mathrm{~b}$ & 99,0 a & $98,0 \mathrm{a}$ & 99,2 a & $98,0 \mathrm{a}$ & 99,2 a & 98,2 a \\
\hline $\begin{array}{l}\text { AI11002-VS } \\
\left(200 \mathrm{~L} \mathrm{ha}^{-1}\right)\end{array}$ & $93,0 \mathrm{a}$ & 93,5 a & $98,2 \mathrm{a}$ & $96,7 \mathrm{~b}$ & 99,0 a & $99,0 \mathrm{a}$ & 99,2 a & 98,5 a & $99,0 \mathrm{a}$ & $99,2 \mathrm{a}$ \\
\hline $\begin{array}{l}\text { TF-VP5 } \\
\left(310 \mathrm{~L} \mathrm{ha}^{-1}\right)\end{array}$ & $95,5 \mathrm{a}$ & $95,0 \mathrm{a}$ & $98,7 \mathrm{a}$ & $99,2 \mathrm{a}$ & $99,0 \mathrm{a}$ & $98,7 \mathrm{a}$ & $99,2 \mathrm{a}$ & $99,0 \mathrm{a}$ & $99,7 \mathrm{a}$ & 99,7 a \\
\hline Testemunha & $0,0 \mathrm{~b}$ & $0,0 \mathrm{~b}$ & $0,0 \mathrm{~b}$ & $0,0 \mathrm{c}$ & $0,0 \mathrm{~b}$ & $0,0 \mathrm{~b}$ & $0,0 \mathrm{~b}$ & $0,0 \mathrm{~b}$ & $0,0 \mathrm{~b}$ & $0,0 \mathrm{~b}$ \\
\hline Herbicidas (H) & \multicolumn{2}{|c|}{$0,61^{\mathrm{NS}}$} & \multicolumn{2}{|c|}{$0,77^{\mathrm{NS}}$} & \multicolumn{2}{|c|}{$0,46^{\mathrm{NS}}$} & \multicolumn{2}{|c|}{$1,48^{\mathrm{NS}}$} & \multicolumn{2}{|c|}{$0,21^{\mathrm{NS}}$} \\
\hline Pontas (P) & \multicolumn{2}{|c|}{$4145,29^{* *}$} & \multicolumn{2}{|c|}{$9822,18^{* *}$} & \multicolumn{2}{|c|}{$11416,37 * *$} & \multicolumn{2}{|c|}{$11435,62 * *$} & \multicolumn{2}{|c|}{$19814,06^{* *}$} \\
\hline $\mathrm{H} \times \mathrm{P}$ & \multicolumn{2}{|c|}{$0,03^{\mathrm{NS}}$} & \multicolumn{2}{|c|}{$0,79^{\mathrm{NS}}$} & \multicolumn{2}{|c|}{$0,26^{\mathrm{NS}}$} & \multicolumn{2}{|c|}{$0,36^{\mathrm{NS}}$} & \multicolumn{2}{|c|}{$0,46^{\mathrm{NS}}$} \\
\hline CV (\%) & \multicolumn{2}{|c|}{2,93} & \multicolumn{2}{|c|}{1,90} & \multicolumn{2}{|c|}{1,77} & \multicolumn{2}{|c|}{1,76} & \multicolumn{2}{|c|}{1,55} \\
\hline DMS (5\%) & \multicolumn{2}{|c|}{3,03} & \multicolumn{2}{|c|}{2,05} & \multicolumn{2}{|c|}{1,92} & \multicolumn{2}{|c|}{1,92} & \multicolumn{2}{|c|}{1,69} \\
\hline
\end{tabular}

1/ Dias após aplicação.

Médias seguidas de mesma letra, minúscula na coluna e maiúscula na linha, não diferem estatisticamente entre si pelo teste $t$ ( $\mathrm{p}<0,05$ ).

$* *=$ valor significativo pelo teste $\mathrm{F}$ a $\mathrm{p}<0,01 ; *=$ valor significativo pelo teste $\mathrm{F}$ a $\mathrm{p}<0,05$; Ns $=$ não-significativo.

aplicados com a ponta TF-VP5, apresentaramse eficientes, proporcionando controle de B. decumbens (plantas grandes) de 91,2\% e $92,5 \%$, respectivamente. Essa eficácia foi mantida até o início do fechamento da cultura, com evidente superioridade em relação aos demais tratamentos.

O trifloxysulfuron-sodium + ametryne, aplicado com a ponta AI 1 1002-VS, apresentou niveis satisfatórios de controle a partir dos 21 DAA (Tabela 4), não diferindo estatistica- mente do hexazinone + diuron, mas com desempenho prejudicado aos 63 DAA, em razão do surgimento de novas rebrotas da infestação. Os tratamentos com a ponta XR11002-VS controlaram insatisfatoriamente $B$. decumbens (plantas grandes), proporcionando, aos 63 DAA, niveis inferiores a $56 \%$. Esses resultados corroboram os obtidos por Schumm \& Braz (2002), os quais, estudando o controle em pósemergência tardia de $B$. decumbens e $D$. horizontalis (3 a 6 perfilhos), não verificaram boa eficiência do trifloxysufuron-sodium 
Tabela 4 - Controle (\%) de Brachiaria decumbens em estádio de 6 a 8 perfilhos aos 7, 14, 21, 28 e 63 dias após a aplicação de trifloxysulfuron-sodium + ametryne $\left(\right.$ Krismat $\left.^{\circledR}\right)$ e hexazinone + diuron $\left(\right.$ Velpar $\left.\mathrm{K}^{\circledR}\right)$ na cultura da cana-de-açúcar

\begin{tabular}{|c|c|c|c|c|c|c|c|c|c|c|}
\hline \multirow{2}{*}{$\begin{array}{c}\text { Pontas de } \\
\text { pulverização }\end{array}$} & \multicolumn{2}{|c|}{$7 \mathrm{DAA}^{1 /}$} & \multicolumn{2}{|c|}{14 DAA } & \multicolumn{2}{|c|}{$21 \mathrm{DAA}$} & \multicolumn{2}{|c|}{$28 \mathrm{DAA}$} & \multicolumn{2}{|c|}{63 DAA } \\
\hline & Krismat $^{\circledR}$ & Velpar $\mathrm{K}^{\circledR}$ & Krismat $^{\circledR}$ & Velpar $\mathrm{K}^{\circledast}$ & Krismat $^{\circledast}$ & Velpar $\mathrm{K}^{\circledast}$ & Krismat $^{\circledR}$ & Velpar $\mathrm{K}^{\circledR}$ & Krismat $^{\circledR}$ & Velpar $\mathrm{K}^{\circledR}$ \\
\hline $\begin{array}{l}\text { XR11002-VS } \\
\left(128 \mathrm{~L} \mathrm{~h}^{-1}\right)\end{array}$ & $60,0 \mathrm{~b}$ & $63,7 \mathrm{~b}$ & $50,0 \mathrm{c} \mathrm{B}$ & $70,0 \mathrm{c} \mathrm{A}$ & $51,2 \mathrm{~b} \mathrm{~B}$ & $68,7 \mathrm{~b} \mathrm{~A}$ & 47,5 b B & $65,5 \mathrm{~b} \mathrm{~A}$ & $46,2 \mathrm{c}$ & $56,2 \mathrm{c}$ \\
\hline $\begin{array}{l}\text { AI11002-VS } \\
\left(200 \mathrm{~L} \mathrm{ha}^{-1}\right)\end{array}$ & $70,0 \mathrm{~b}$ & $75,0 \mathrm{~b}$ & $75,0 \mathrm{~b} \mathrm{~A}$ & 81,2 b A & 80,0 a A & 88,2 a A & 80,0 a A & 86,7 a A & $72,5 \mathrm{~b}$ & $78,7 \mathrm{~b}$ \\
\hline $\begin{array}{l}\text { TF-VP5 } \\
\left(310 \mathrm{~L} \mathrm{ha}^{-1}\right) \\
\end{array}$ & $86,2 \mathrm{a}$ & $82,5 \mathrm{a}$ & 91,2 a A & 92,5 a A & 91,2 a A & 94,5 a A & 90,2 a A & 93,7 a A & $91,2 \mathrm{a}$ & $91,2 \mathrm{a}$ \\
\hline Testemunha & $0,0 \mathrm{c}$ & $0,0 \mathrm{c}$ & $0,0 \mathrm{~d} \mathrm{~A}$ & $0,0 \mathrm{~d} \mathrm{~A}$ & $0,0 \mathrm{c} \mathrm{A}$ & $0,0 \mathrm{c} \mathrm{A}$ & $0,0 \mathrm{cA}$ & $0,0 \mathrm{c} \mathrm{A}$ & $0,0 \mathrm{~d}$ & $0,0 \mathrm{~d}$ \\
\hline Herbicidas $(\mathrm{H})$ & \multicolumn{2}{|c|}{$0,22^{\mathrm{NS}}$} & \multicolumn{2}{|c|}{$8,09 * *$} & \multicolumn{2}{|c|}{$5,02 *$} & \multicolumn{2}{|c|}{$4,60^{*}$} & \multicolumn{2}{|c|}{$2,31^{\mathrm{NS}}$} \\
\hline Pontas (P) & \multicolumn{2}{|c|}{$202,66^{* *}$} & \multicolumn{2}{|c|}{$280,76^{* *}$} & \multicolumn{2}{|c|}{$167,55^{* *}$} & \multicolumn{2}{|c|}{$158,81^{* *}$} & \multicolumn{2}{|c|}{223,39 ** } \\
\hline $\mathrm{H} \times \mathrm{P}$ & \multicolumn{2}{|c|}{$0,56^{\mathrm{NS}}$} & \multicolumn{2}{|c|}{$3,59 *$} & \multicolumn{2}{|c|}{$1,39^{\mathrm{NS}}$} & \multicolumn{2}{|c|}{$1,40^{\mathrm{NS}}$} & \multicolumn{2}{|c|}{$0,85^{\mathrm{NS}}$} \\
\hline CV (\%) & \multicolumn{2}{|c|}{13,66} & \multicolumn{2}{|c|}{11,89} & \multicolumn{2}{|c|}{15,44} & \multicolumn{2}{|c|}{16,07} & \multicolumn{2}{|c|}{13,85} \\
\hline DMS (5\%) & \multicolumn{2}{|c|}{10,98} & \multicolumn{2}{|c|}{10,05} & \multicolumn{2}{|c|}{13,46} & \multicolumn{2}{|c|}{13,70} & \multicolumn{2}{|c|}{11,11} \\
\hline
\end{tabular}

1/ Dias após aplicação.

Médias seguidas de mesma letra, minúscula na coluna e maiúscula na linha, não diferem estatisticamente entre si pelo teste $t$ ( $\mathrm{p}<0,05$ ).

$* *=$ valor significativo pelo teste $\mathrm{F}$ a $\mathrm{p}<0,01 ; *=$ valor significativo pelo teste $\mathrm{F}$ a $\mathrm{p}<0,05$; Ns $=$ não-significativo.

+ ametryne, a não ser quando utilizado em mistura com MSMA.

Aos 7 DAA, os herbicidas trifloxysulfuronsodium + ametryne e hexazinone + diuron, nas diferentes modalidades de pulverização, promoveram niveis de injúria acentuados na parte aérea das plantas de cana-de-açúcar, nas duas condições de manejo de palha (Tabelas 5 e 6). Os sintomas de clorose e bronzeamento seguidos de necrose das pontas e bordas das folhas foram danos visuais provocados de forma mais intensa até 14 DAA. Nesse período, os herbicidas com as pontas TF-VP5 e AI 1 1002-VS apresentaram as maiores porcentagens de injúrias visuais à cultura, tendo o trifloxysulfuron-sodium + ametryne sido mais seletivo que o hexazinone + diuron. A partir dos 21 DAA, os danos não foram mais verificados nas folhas mais novas da cultura, porém ainda persistiram nas folhas intermediárias até os 28 DAA, nas duas modalidades de manejo de palha. Aos 63 DAA, os efeitos de toxidez visual à cultura não foram mais observados. Resultados semelhantes foram relatados por Terra (2003), em estudo de seletividade, mencionando a persistência das injúrias dos herbicidas à base de ametryne e sua mistura com trifloxysulfuron-sodium, influenciando diretamente a atribuição das notas de toxicidade.

Nas Tabelas 7 e 8 encontram-se os resultados de controle geral da infestação e de alguns parâmetros culturais aos 90 DAA, considerando as condições de palhada manejada ou cana crua. Os herbicidas trifloxysulfuronsodium + ametryne e hexazinone + diuron, aplicados em palhada manejada, proporcionaram controle geral eficiente $(91,25 \%)$ com a ponta TF-VP5 e satisfatório com a ponta AI11002-VS (80,0 e 88,7\%), aos 90 DAA (Tabela 7). A ponta XR11002-VS, combinada aos herbicidas estudados em palhada manejada, apresentou-se deficiente no controle total da infestação. Na condição de cana crua sem retirada da palha da linha da plantio, todos os tratamentos apresentaram controle excelente de $B$. decumbens e $D$. horizontalis, provavelmente devido à presença da palha na superficie do solo. Esses resultados concordam com os obtidos por Gravena et al. (2002) e Negrisoli et al. (2002).

Quanto às variáveis altura da cana, número de perfilhos e diâmetro de colmos aos 90 DAA, não houve diferenças significativas nas duas condições de manejo de palha (Tabelas 7 e 8). Para os parâmetros altura da cana, número de perfilhos e diâmetro de colmos aos 90 DAA, não houve diferenças significativas nas duas condições de manejo de palha (Tabelas 7 e 8). Entretanto, em palhada retirada da linha de plantio, a altura das plantas de cana-de-açúcar submetidas à aplicação de trifloxysulfuron-sodium + ametryne com as pontas AI11002-VS e TF-VP5 apresentou-se 
Tabela 5 - Toxicidade (\%) na cultura da cana-de-açúcar aos 7, 14, 21, 28 e 63 dias após a aplicação de trifloxysulfuron-sodium + ametryne $\left(\right.$ Krismat $\left.^{\circledR}\right)$ e hexazinone + diuron $\left(\right.$ Velpar $\mathrm{K}^{\circledR}$ ) para ausência de palha na linha de plantio (palhada manejada)

\begin{tabular}{|c|c|c|c|c|c|c|c|c|c|c|}
\hline \multirow{2}{*}{$\begin{array}{c}\text { Pontas de } \\
\text { pulverização }\end{array}$} & \multicolumn{2}{|c|}{$7 \mathrm{DAA}^{1 /}$} & \multicolumn{2}{|c|}{$14 \mathrm{DAA}$} & \multicolumn{2}{|c|}{$21 \mathrm{DAA}$} & \multicolumn{2}{|c|}{$28 \mathrm{DAA}$} & \multicolumn{2}{|c|}{$63 \mathrm{DAA}$} \\
\hline & Krismat $^{(8)}$ & Velpar $\mathrm{K}^{\circledR}$ & Krismat $^{(\otimes)}$ & Velpar K ${ }^{\circledR}$ & Krismat $^{(\otimes)}$ & Velpar $\mathrm{K}^{\circledR}$ & Krismat $^{(B)}$ & Velpar $\mathrm{K}^{\circledR}$ & Krismat $^{(B)}$ & ${\text { Velpar } \mathrm{K}^{\circledR}}^{\circledR}$ \\
\hline $\begin{array}{l}\text { XR11002-VS } \\
\left(128 \mathrm{~L} \mathrm{ha}^{-1}\right)\end{array}$ & 13,7 a A & 11,2 a A & 9,0 a C & $12,5 \mathrm{a} \mathrm{C}$ & 4,5 a B & 6,5 a C & $1,2 \mathrm{a} \quad \mathrm{BC}$ & 2,7 a C & 0,0 & 0,0 \\
\hline $\begin{array}{l}\text { AI11002-VS } \\
\left(200 \mathrm{~L} \mathrm{ha}^{-1}\right)\end{array}$ & 14,5 a A & 15,0 a A & 15,0 a B & 18,2 a B & $7,5 \mathrm{~b} \mathrm{~B}$ & 14,5 a B & $3,2 \mathrm{~b} \mathrm{AB}$ & 5,7 a B & 0,0 & 0,0 \\
\hline $\begin{array}{l}\text { TF-VP5 } \\
\left(310 \mathrm{~L} \mathrm{ha}^{-1}\right)\end{array}$ & 20,0 a A & 17,5 a A & $21,2 \mathrm{~b} \mathrm{~A}$ & 27,0 a A & $13,2 \mathrm{~b} \mathrm{~A}$ & 23,7 a A & $5,0 \mathrm{~b} \mathrm{~A}$ & 10,2 a A & 0,0 & 0,0 \\
\hline Testemunha & 0,0 a B & 0,0 a B & 0,0 a D & 0,0 a D & $0,0 \mathrm{a} \mathrm{C}$ & 0,0 a D & $0,0 \mathrm{a} \quad \mathrm{C}$ & 0,0 a D & 0,0 & 0,0 \\
\hline Herbicidas $(\mathrm{H})$ & \multicolumn{2}{|c|}{$0,47^{\mathrm{NS}}$} & \multicolumn{2}{|c|}{$11,93^{* *}$} & \multicolumn{2}{|c|}{$33,14 * *$} & \multicolumn{2}{|c|}{$16,66^{* *}$} & \multicolumn{2}{|c|}{-} \\
\hline Pontas (P) & \multicolumn{2}{|c|}{$24,39 * *$} & \multicolumn{2}{|c|}{$126,62 * *$} & \multicolumn{2}{|c|}{$91,15^{* *}$} & \multicolumn{2}{|c|}{$33,77 * *$} & \multicolumn{2}{|c|}{ - } \\
\hline $\mathrm{H} \times \mathrm{P}$ & \multicolumn{2}{|c|}{$0,24^{\mathrm{NS}}$} & \multicolumn{2}{|c|}{$1,71^{\mathrm{NS}}$} & \multicolumn{2}{|c|}{$8,11 * *$} & \multicolumn{2}{|c|}{$3,81^{*}$} & \multicolumn{2}{|c|}{-} \\
\hline $\mathrm{CV}(\%)$ & \multicolumn{2}{|c|}{40,29} & \multicolumn{2}{|c|}{19,87} & \multicolumn{2}{|c|}{26,86} & \multicolumn{2}{|c|}{45,37} & \multicolumn{2}{|c|}{-} \\
\hline DMS (5\%) & \multicolumn{2}{|c|}{6,81} & \multicolumn{2}{|c|}{3,76} & \multicolumn{2}{|c|}{3,43} & \multicolumn{2}{|c|}{2,36} & \multicolumn{2}{|c|}{-} \\
\hline
\end{tabular}

1/ Dias após aplicação.

Médias seguidas de mesma letra, minúscula na coluna e maiúscula na linha, não diferem estatisticamente entre si pelo teste $t$ ( $\mathrm{p}<0,05$ ). $* *$ = valor significativo pelo teste $\mathrm{F}$ a $\mathrm{p}<0,01 ; *=$ valor significativo pelo teste $\mathrm{F} \mathrm{a} \mathrm{p}<0,05$; Ns $=$ não-significativo.

Tabela 6 - Toxicidade (\%) na cultura da cana-de-açúcar aos 7, 14, 21, 28 e 63 dias após a aplicação de trifloxysulfuron-sodium + ametryne $\left(\right.$ Krismat $\left.^{\circledR}\right)$ e hexazinone + diuron $\left(\right.$ Velpar $\mathrm{K}^{\circledR}$ ) para presença de palha na linha de plantio (cana crua)

\begin{tabular}{|c|c|c|c|c|c|c|c|c|c|c|}
\hline \multirow{2}{*}{$\begin{array}{c}\text { Pontas de } \\
\text { pulverização }\end{array}$} & \multicolumn{2}{|c|}{$7 \mathrm{DAA}^{1 / /}$} & \multicolumn{2}{|c|}{14 DAA } & \multicolumn{2}{|c|}{21 DAA } & \multicolumn{2}{|c|}{28 DAA } & \multicolumn{2}{|c|}{63 DAA } \\
\hline & Krismat $^{\circledR}$ & Velpar $\mathrm{K}^{\circledast}$ & Krismat $^{\circledast}$ & Velpar $\mathrm{K}^{\circledast}$ & Krismat $^{\circledR}$ & Velpar $\mathrm{K}^{(}$ & Krismat $^{\circledast}$ & Velpar $\mathrm{K}^{\circledast}$ & Krismat $^{\circledR}$ & Velpar K ${ }^{\sqrt{8}}$ \\
\hline $\begin{array}{l}\text { XR11002-VS } \\
\left(128 \mathrm{~L} \mathrm{ha}^{-1}\right)\end{array}$ & $12,5 \mathrm{~b}$ & $11,2 \mathrm{~b}$ & $10,2 \mathrm{c} \mathrm{A}$ & $8,2 \mathrm{c} \mathrm{A}$ & $3,7 \mathrm{c} \mathrm{A}$ & $4,0 \mathrm{c} \mathrm{A}$ & $0,7 \mathrm{~b} \mathrm{~A}$ & $1,0 \mathrm{c} \mathrm{A}$ & 0,0 & 0,0 \\
\hline $\begin{array}{l}\text { AI11002-VS } \\
\left(200 \mathrm{~L} \mathrm{ha}^{-1}\right) \\
\end{array}$ & $14,5 \mathrm{~b}$ & $13,0 \mathrm{~b}$ & 14,5 b B & $17,5 \mathrm{~b} \mathrm{~A}$ & 7,5 b B & $12,0 \mathrm{~b} \mathrm{~A}$ & 3,0 a B & $5,7 \mathrm{bA}$ & 0,0 & 0,0 \\
\hline $\begin{array}{l}\text { TF-VP5 } \\
\left(310 \mathrm{~L} \mathrm{ha}^{-1}\right) \\
\end{array}$ & $19,5 \mathrm{a}$ & $17,5 \mathrm{a}$ & 17,5 a B & 25,5 a A & 10,7 a B & 21,2 a A & 4,2 a B & 9,5 a A & 0,0 & 0,0 \\
\hline Testemunha & $0,0 \mathrm{c}$ & $0,0 \mathrm{c}$ & $0,0 \mathrm{dA}$ & $0,0 \mathrm{dA}$ & $0,0 \mathrm{dA}$ & $0,0 \mathrm{dA}$ & $0,0 \mathrm{~b} \mathrm{~A}$ & $0,0 \mathrm{c} \mathrm{A}$ & 0,0 & 0,0 \\
\hline Herbicidas $(\mathrm{H})$ & \multicolumn{2}{|c|}{$1,83^{\mathrm{NS}}$} & \multicolumn{2}{|c|}{$10,21^{* *}$} & \multicolumn{2}{|c|}{$43,68^{* *}$} & \multicolumn{2}{|c|}{$17,47 * *$} & \multicolumn{2}{|c|}{-} \\
\hline Pontas (P) & \multicolumn{2}{|c|}{$80,31^{* *}$} & \multicolumn{2}{|c|}{$172,90^{* *}$} & \multicolumn{2}{|c|}{$146,91^{* *}$} & \multicolumn{2}{|c|}{$41,64 * *$} & \multicolumn{2}{|c|}{-} \\
\hline $\mathrm{H} \times \mathrm{P}$ & \multicolumn{2}{|c|}{$0,23^{\mathrm{NS}}$} & \multicolumn{2}{|c|}{$9,53 * *$} & \multicolumn{2}{|c|}{$18,14^{* *}$} & \multicolumn{2}{|c|}{$6,22 * *$} & \multicolumn{2}{|c|}{-} \\
\hline CV (\%) & \multicolumn{2}{|c|}{22,50} & \multicolumn{2}{|c|}{17,05} & \multicolumn{2}{|c|}{22,03} & \multicolumn{2}{|c|}{46,04} & \multicolumn{2}{|c|}{ - } \\
\hline DMS (5\%) & \multicolumn{2}{|c|}{3,65} & \multicolumn{2}{|c|}{2,93} & \multicolumn{2}{|c|}{2,40} & \multicolumn{2}{|c|}{2,05} & \multicolumn{2}{|c|}{-} \\
\hline
\end{tabular}

1/ Dias após aplicação.

Médias seguidas de mesma letra, minúscula na coluna e maiúscula na linha, não diferem estatisticamente entre si pelo teste $t$ ( $\mathrm{p}<0,05$ ). $* *$ = valor significativo pelo teste $\mathrm{F}$ a $\mathrm{p}<0,01 ; *=$ valor significativo pelo teste $\mathrm{F}$ a $\mathrm{p}<0,05$; Ns $=$ não-significativo.

significativamente superior à daquelas submetidas ao herbicida hexazinone + diuron. Para hexazinone + diuron aplicado com a ponta XR 110.02-VS, também foi constatado que a altura das plantas de cana-de-açúcar foi superior aos modelos AI11002-VS e TF-VP5.

No segundo experimento, as curvas da freqüência acumulada (\%) dos depósitos da calda de pulverização $\left(\mu \mathrm{L} \mathrm{cm}{ }^{-2}\right)$ ajustaram-se satisfatoriamente ao modelo de Gompertz, apresentando elevados coeficientes de determinação
( $\mathrm{R}^{2}$ entre 0,9698 e 0,9936), independentemente da calda de pulverização utilizada (Figura 2).

Os dados originais demonstram que as relações entre o maior e o menor depósito sobre as plântulas de $D$. horizontalis, utilizando-se as pontas XR1 1002-VS, AI11002-VS e TF-VP5, foram de aproximadamente 10,4, 18,6 e 8,6 vezes para a calda com FDC- 1 + trifloxysulfuron sodium + ametryne e de 5,1,11,42 e 8,5 vezes para a calda com FDC-1 + hexazinone + diuron, respectivamente. Entretanto, na Figura 2 
Tabela 7 - Controle geral da infestação e alguns parâmetros culturais para ausência de palha na linha de plantio (palhada manejada) aos 90 dias após a aplicação de trifloxysulfuron-sodium + ametryne $\left(\operatorname{Krismat}^{\circledR}\right)$ e hexazinone + diuron $\left(\right.$ Velpar $\left.\mathrm{K}^{\circledR}\right)$

\begin{tabular}{|c|c|c|c|c|c|c|c|c|}
\hline \multirow{2}{*}{$\begin{array}{c}\text { Pontas de } \\
\text { pulverização }\end{array}$} & \multicolumn{2}{|c|}{ Controle geral (\%) } & \multicolumn{2}{|c|}{ Altura da cana $(\mathrm{cm})$} & \multicolumn{2}{|c|}{ № de perfilhos $/ \mathrm{m}$} & \multicolumn{2}{|c|}{ Diâmetro de colmo (mm) } \\
\hline & Krismat $^{\circledR}$ & Velpar $\mathrm{K}^{\circledR}$ & Krismat $^{\circledR}$ & Velpar $\mathrm{K}^{\circledR}$ & Krismat $^{\circledR}$ & Velpar $\mathrm{K}^{\circledR}$ & Krismat $^{\circledR}$ & Velpar $\mathrm{K}^{\circledR}$ \\
\hline $\begin{array}{l}\text { XR11002-VS } \\
\left(128 \mathrm{~L} \mathrm{~h}^{-1}\right)\end{array}$ & $53,7 \mathrm{~b}$ & $57,5 \mathrm{~b}$ & 124,8 a A & 120,8 a A & 22,2 & 21,2 & 27,5 & 25,4 \\
\hline $\begin{array}{l}\text { AI11002-VS } \\
\left(200 \mathrm{~L} \mathrm{ha}^{-1}\right)\end{array}$ & $80,0 \mathrm{a}$ & 88,7 a & 120,9 a A & 114,9 b B & 23,5 & 21,5 & 25,9 & 26,9 \\
\hline $\begin{array}{l}\text { TF-VP5 } \\
\left(310 \mathrm{~L} \mathrm{ha}^{-1}\right)\end{array}$ & $91,2 \mathrm{a}$ & $93,2 \mathrm{a}$ & 121,8 a A & 112,2 b B & 21,2 & 20,2 & 25,9 & 24,9 \\
\hline Testemunha & $0,0 \mathrm{c}$ & $0,0 \mathrm{c}$ & 122,9 a A & $116,9 \mathrm{ab} B$ & 23,7 & 21,2 & 26,4 & 25,9 \\
\hline Herbicidas (H) & \multicolumn{2}{|c|}{$1,418^{\mathrm{NS}}$} & \multicolumn{2}{|c|}{$0,231^{* *}$} & \multicolumn{2}{|c|}{$9,697^{\mathrm{NS}}$} & \multicolumn{2}{|c|}{$1,760^{\mathrm{NS}}$} \\
\hline Pontas (P) & \multicolumn{2}{|c|}{$188,481^{* *}$} & \multicolumn{2}{|c|}{$0,204 *$} & \multicolumn{2}{|c|}{$2,525^{\mathrm{NS}}$} & \multicolumn{2}{|c|}{$1,053^{\mathrm{NS}}$} \\
\hline $\mathrm{H} \times \mathrm{P}$ & \multicolumn{2}{|c|}{$0,378^{\mathrm{NS}}$} & \multicolumn{2}{|c|}{$1,723^{\mathrm{NS}}$} & \multicolumn{2}{|c|}{$0,516^{\mathrm{NS}}$} & \multicolumn{2}{|c|}{$1,751^{\mathrm{NS}}$} \\
\hline CV (\%) & \multicolumn{2}{|c|}{14,83} & \multicolumn{2}{|c|}{3,13} & \multicolumn{2}{|c|}{-} & \multicolumn{2}{|c|}{-} \\
\hline DMS (5\%) & \multicolumn{2}{|c|}{12,65} & \multicolumn{2}{|c|}{5,50} & \multicolumn{2}{|c|}{ - } & \multicolumn{2}{|c|}{-} \\
\hline
\end{tabular}

Médias seguidas de mesma letra, minúscula na coluna e maiúscula na linha, não diferem estatisticamente entre si pelo teste $t$ ( $\mathrm{p}<0,05$ ). $* *=$ valor significativo pelo teste $\mathrm{F}$ a $\mathrm{p}<0,01 ; *=$ valor significativo pelo teste $\mathrm{F}$ a $\mathrm{p}<0,05$; Ns $=$ não-significativo.

Tabela 8 - Controle geral da infestação e alguns parâmetros culturais para presença de palha na linha de plantio (cana crua) aos 90 dias após a aplicação de trifloxysulfuron-sodium + ametryne $\left(\right.$ Krismat $\left.^{\circledR}\right)$ e hexazinone + diuron $\left(\right.$ Velpar $\left.^{\circledR}{ }^{\circledR}\right)$

\begin{tabular}{|c|c|c|c|c|c|c|c|c|}
\hline \multirow{2}{*}{$\begin{array}{c}\text { Pontas de } \\
\text { pulverização }\end{array}$} & \multicolumn{2}{|c|}{ Controle geral (\%) } & \multicolumn{2}{|c|}{ Altura da cana $(\mathrm{cm})$} & \multicolumn{2}{|c|}{$\mathrm{N}^{\mathrm{o}}$ de perfilhos/m } & \multicolumn{2}{|c|}{ Diâmetro de colmo (mm) } \\
\hline & Krismat $^{\otimes}$ & Velpar $\mathrm{K}^{(}$ & Krismat $^{\circledast}$ & Velpar $\mathrm{K}^{\circledR}$ & Krismat $^{\circledast}$ & Velpar $\mathrm{K}^{\circledR}$ & Krismat $^{\circledast}$ & Velpar $\mathrm{K}^{\circledR}$ \\
\hline $\begin{array}{l}\text { XR11002-VS } \\
\left(128 \mathrm{~L} \mathrm{ha}^{-1}\right)\end{array}$ & 100,0 & 100,0 & 106,9 & 105,4 & 24,2 & 22,5 & 26,3 & 26,5 \\
\hline $\begin{array}{l}\text { AI11002-VS } \\
\left(200 \mathrm{~L} \mathrm{ha}^{-1}\right)\end{array}$ & 100,0 & 100,0 & 108,1 & 104,6 & 23,2 & 21,5 & 26,1 & 26,8 \\
\hline $\begin{array}{l}\text { TF-VP5 } \\
\left(310 \mathrm{~L} \mathrm{ha}^{-1}\right) \\
\end{array}$ & 100,0 & 100,0 & 103,6 & 106,0 & 22,5 & 23,0 & 26,7 & 26,5 \\
\hline Testemunha & 100,0 & 100,0 & 102,7 & 108,3 & 22,5 & 22,5 & 26,6 & 26,4 \\
\hline Herbicidas $(\mathrm{H})$ & & & \multicolumn{2}{|c|}{$0,231^{\mathrm{NS}}$} & \multicolumn{2}{|c|}{$3,000^{\mathrm{NS}}$} & \multicolumn{2}{|c|}{$0,161^{\mathrm{NS}}$} \\
\hline Pontas (P) & \multicolumn{2}{|c|}{ - } & \multicolumn{2}{|c|}{$0,204^{\mathrm{NS}}$} & \multicolumn{2}{|c|}{$1,056^{\mathrm{NS}}$} & \multicolumn{2}{|c|}{$0,050^{\mathrm{NS}}$} \\
\hline $\mathrm{H} \times \mathrm{P}$ & \multicolumn{2}{|c|}{-} & \multicolumn{2}{|c|}{$1,723^{\mathrm{NS}}$} & \multicolumn{2}{|c|}{$1,833^{\mathrm{NS}}$} & \multicolumn{2}{|c|}{$0,273^{\mathrm{NS}}$} \\
\hline CV (\%) & & & \multicolumn{2}{|c|}{-} & \\
\hline DMS (5\%) & \multicolumn{2}{|c|}{-} & \multicolumn{2}{|c|}{-} & \multicolumn{2}{|c|}{ - } & \multicolumn{2}{|c|}{-} \\
\hline
\end{tabular}

NS = não-significativo.

(Aa e Ba) as curvas das freqüências acumuladas (\%) indicam que a uniformidade de deposição das caldas dos herbicidas em $D$. horizontalis apresentou-se bastante semelhante para as três pontas de pulverização quando se utilizaram as soluções de FDC-1 + trifloxysulfuron-sodium + ametryne e FDC-1 + hexazinone + diuron. Esse fato é pela similaridade na inclinação das curvas, comparadose as pontas iguais para as caldas de herbicidas diferentes, ou ainda pelos valores do parâmetro "c" do modelo de Gompertz (Tabela 9), em que os maiores valores de "c" indicam as menores inclinações das curvas e, conseqüentemente, a maior uniformidade dos depósitos da calda de pulverização.

Com base nos resultados obtidos, pode-se exemplificar que, se a dose minima necessária para matar as plantas de $D$. horizontalis estivesse contida em $0,5 \mu \mathrm{L} \mathrm{cm} \mathrm{cm}^{-2}$, haveria apenas 23,5 e 0,5\%; 20,3 e 15,6\%; e 5,6 e 7,1\% de escape de controle para as pontas XR11002VS, AI11002-VS e TF-VP5, utilizando-se os 

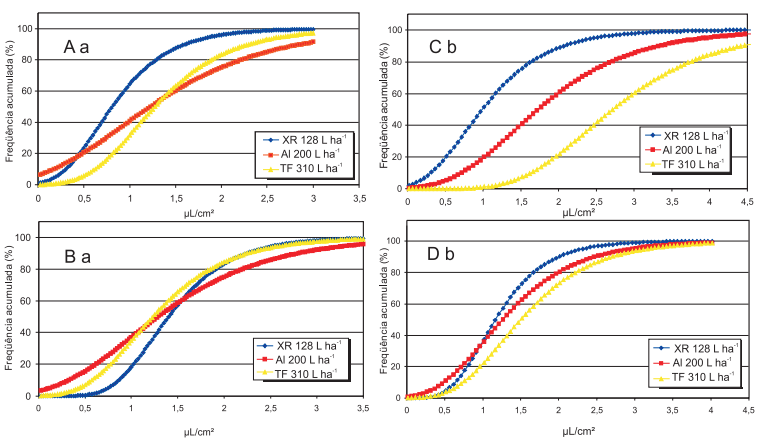

Figura 2 - Freqüências acumuladas (\%) em função do volume das soluções de FDC-1 + trifloxysulfuronsodium+ametryne (A e C) e FDC-1 + hexazinone+diuron (B e D) pulverizadas com diferentes pontas e depositadas por unidade de área foliar de Digitaria horizontalis (a) e cana-de-açúcar (b), utilizando-se o modelo de Gompertz. herbicidas trifloxysulfuron-sodium + ametryne e hexazinone + diuron, respectivamente (Figura $2 \mathrm{Aa}$ e Ba). Apesar da ineficiência de controle do trifloxysulfuron-sodium + ametryne com a ponta XR11002-VS, em comparação ao hexazinone + diuron, ao confrontar os dados de deposição e controle (Figura 9 e Tabela 1), observa-se que o controle apresentou-se semelhante para ambos os produtos, apesar de sua menor homogeneidade de deposição.

Além disso, ainda na Tabela 9, pode-se constatar através da moda (maior freqüência dos valores) o menor valor de depósito de FDC$1+$ trifloxysulfuron-sodium + ametryne em D. horizontalis para a ponta XR11002-VS, quando comparada com as outras pontas, fato esse que coincide com os menores niveis de

Tabela 9 - Resultados das análises de regressão entre freqüências acumuladas (\%) e os depósitos da solução pulverizada, utilizando o modelo de Gompertz, considerando os herbicidas trifloxysulfuron-sodium + ametryne (Krismat ${ }^{\circledR}$ ) e hexazinone + diuron (Velpar $\mathrm{K}^{\circledR}$ ), os alvos cana-de-açúcar e $D$. horizontalis e as diferentes pontas de pulverização em manejo da palha na linha de plantio

\begin{tabular}{|c|c|c|c|c|c|c|c|}
\hline \multirow{3}{*}{$\begin{array}{c}\text { Pontas de } \\
\text { pulverização }\end{array}$} & \multicolumn{7}{|c|}{ Frequêencia acumulada $(\%)=\mathrm{e}^{\wedge}\left(\mathrm{a}-\mathrm{e}^{\wedge}\left(-\mathrm{b}-\mathrm{c}^{*} \mathrm{X}\right)\right)$} \\
\hline & \multicolumn{4}{|c|}{ Krismat $^{\circledR}$ para $D$. horizontalis $\left(\mu \mathrm{L} \mathrm{cm}^{-2}\right)$} & \multicolumn{3}{|c|}{ Velpar $\mathrm{K}^{\oplus}$ para D. horizontalis $\left(\mu \mathrm{L} \mathrm{cm}^{-2}\right)$} \\
\hline & & $\begin{array}{l}\text { XR11002-VS } \\
\left(128 \mathrm{~L} \mathrm{ha}^{-1}\right)\end{array}$ & $\begin{array}{l}\text { AI11002-VS } \\
\left(200 \mathrm{~L} \mathrm{ha}^{-1}\right)\end{array}$ & $\begin{array}{c}\text { TF-VP5 } \\
\left(310 \mathrm{~L} \mathrm{ha}^{-1}\right)\end{array}$ & $\begin{array}{l}\text { XR11002-VS } \\
\left(128 \mathrm{~L} \mathrm{ha}^{-1}\right)\end{array}$ & $\begin{array}{l}\text { AI11002-VS } \\
\left(200 \mathrm{~L} \mathrm{ha}^{-1}\right)\end{array}$ & $\begin{array}{c}\text { TF-VP5 } \\
\left(310 \mathrm{~L} \mathrm{ha}^{-1}\right)\end{array}$ \\
\hline \multirow{3}{*}{$\begin{array}{c}\text { Estimativa dos } \\
\text { parâmetros }\end{array}$} & A & 4,6052 & 4,6052 & 4,6052 & 4,6052 & 4,6052 & 4,6052 \\
\hline & B & $-1,5551$ & $-1,0364$ & $-1,9771$ & $-2,7605$ & $-1,2415$ & $-1,8884$ \\
\hline & $\mathrm{C}$ & 2,3718 & 1,1432 & 1,8378 & 2,2288 & 1,2453 & 1,8312 \\
\hline Média & & 0,9157 & 1,6292 & 1,4479 & 1,5024 & 1,5436 & 1,3532 \\
\hline Moda & & 0,6557 & 0,9065 & 1,0758 & 1,2385 & 0,9969 & 1,0312 \\
\hline Mediana & & 0,5011 & 0,5859 & 0,8766 & 1,0741 & 0,7026 & 0,8311 \\
\hline $\mathrm{N}^{\mathrm{o}}$ repetições & & 30 & 30 & 30 & 30 & 30 & 30 \\
\hline $\mathrm{R}^{2}$ & & 0,9887 & 0,9836 & 0,9935 & 0,9873 & 0,9894 & 0,9872 \\
\hline F Regressão & & $52383,05^{* *}$ & $52313,98^{* *}$ & $52449,83^{* *}$ & $52364,30^{* *}$ & $52393,79 * *$ & $52363,45^{* *}$ \\
\hline S Q Resíduo & & 313,90 & 452,03 & 180,32 & 351,40 & 292,41 & 353,09 \\
\hline \multirow{2}{*}{$\begin{array}{c}\text { Pontas de } \\
\text { pulverização }\end{array}$} & \multicolumn{4}{|c|}{ Krismat $^{\circledR}$ para cana-de-açúcar $\left(\mu \mathrm{L} \mathrm{cm}^{-2}\right)$} & \multicolumn{3}{|c|}{ Velpar $\mathrm{K}^{\circledast}$ para cana-de-açúcar $\left(\mu \mathrm{L} \mathrm{cm}^{-2}\right)$} \\
\hline & & $\begin{array}{l}\text { XR11002-VS } \\
\left(128 \mathrm{~L} \mathrm{ha}^{-1}\right)\end{array}$ & $\begin{array}{l}\text { AI11002-VS } \\
\left(200 \mathrm{~L} \mathrm{ha}^{-1}\right)\end{array}$ & $\begin{array}{c}\text { TF-VP5 } \\
\left(310 \mathrm{~L} \mathrm{ha}^{-1}\right)\end{array}$ & $\begin{array}{c}\text { XR11002-VS } \\
\left(128 \mathrm{~L} \mathrm{ha}^{-1}\right)\end{array}$ & $\begin{array}{l}\text { AI11002-VS } \\
\left(200 \mathrm{~L} \mathrm{ha}^{-1}\right)\end{array}$ & $\begin{array}{c}\text { TF-VP5 } \\
\left(310 \mathrm{~L} \mathrm{ha}^{-1}\right)\end{array}$ \\
\hline \multirow{3}{*}{$\begin{array}{c}\text { Estimativa dos } \\
\text { parâmetros }\end{array}$} & A & 4,6052 & 4,6052 & 4,6052 & 4,6052 & 4,6052 & 4,6052 \\
\hline & $\mathrm{B}$ & $-1,3671$ & $-1,6723$ & $-2,6334$ & $-2,2882$ & $-1,5937$ & $-1,9963$ \\
\hline & $\mathrm{C}$ & 1,7520 & 1,1779 & 1,1041 & 2,2727 & 1,5502 & 1,5732 \\
\hline Média & & 1,3729 & 1,9446 & 2,8939 & 1,2646 & 1,3923 & 1,7743 \\
\hline Moda & & 0,7803 & 1,4197 & 2,3850 & 1,0068 & 1,0281 & 1,2689 \\
\hline Mediana & & 0,5710 & 1,1086 & 2,0531 & 0,8455 & 0,7916 & 1,0360 \\
\hline $\mathrm{N}^{\mathrm{o}}$ repetições & & 20 & 20 & 20 & 20 & 20 & 20 \\
\hline $\mathrm{R}^{2}$ & & 0,9869 & 0,9698 & 0,9828 & 0,9861 & 0,9778 & 0,9847 \\
\hline F Regressão & & $35749,39 * *$ & $35584,60^{* *}$ & $35709,32^{* *}$ & $35741,69^{* *}$ & $35661,86^{* *}$ & $35727,42^{* *}$ \\
\hline S Q Resíduo & & 251,20 & 580,78 & 331,36 & 266,61 & 426,28 & 295,15 \\
\hline
\end{tabular}

$* *=$ valor significativo pelo teste $\mathrm{F}$ a $\mathrm{p}<0,01 ; *=$ valor significativo pelo teste $\mathrm{F}$ a $\mathrm{p}<0,05$; Ns = não-significativo. 
controle obtidos no primeiro experimento. $\mathrm{O}$ contrário ocorreu com a calda FDC-1 + hexazinone + diuron, na qual as pontas de pulverização apresentaram entre si menores valores modais da deposição em $D$. horizontalis e, conseqüentemente, eficácia de controle similar entre elas, no primeiro experimento.

A variação de deposição da calda de FDC-1 + trifloxysulfuron-sodium + ametryne na canade-açúcar apresentou-se menos homogênea em relação a FDC-1 + hexazinone + diuron, para todas as pontas de pulverização (Figura 2 $\mathrm{Cb}$ e $\mathrm{Db}$ ). As pontas TF-VP5 e AI11002-VS, utilizadas com FDC-1 + trifloxysulfuron-sodium + ametryne, proporcionaram os maiores valores médios, modais e medianos (Tabela 9); entretanto, não foram os tratamentos que proporcionaram os maiores niveis de injúrias à cana-de-açúcar no primeiro experimento. Esse fato pode ser justificado pela habilidade diferenciada de desintoxificação da cultura, uma vez que a variedade estudada aparentemente apresentou-se mais sensivel ao herbicida hexazinone + diuron.

Na Figura 3 encontram-se os valores médios do comportamento dos depósitos pulverizados no solo, os quais foram monitorados através de alvos artificiais, representados por lâminas de vidro dispostas nas entrelinhas da cultura. Os dados sugerem valores progressivos de deposição conforme os volumes de calda utilizados; cada $1 \mu \mathrm{L} \mathrm{cm}^{-2}$ de depósito nas lâminas corresponde a $100 \mathrm{~L} \mathrm{ha}^{-1}$ da calda de pulverização. Os herbicidas estudados apresentam efeito de ação combinada de pré e pósemergência em suas formulações e, nesse sentido, a persistência do efeito residual é função da quantidade a ser depositada no solo.

É importante ressaltar que as pontas de pulverização estudadas apresentam comportamentos distintos de formação de gotas e volume de calda, as quais influenciam diretamente o comportamento da pulverização e, conseqüentemente, a eficiência biológica. Dessa forma, nas condições estudadas, observou-se que o estádio de desenvolvimento da infestação foi parâmetro fundamental para o desempenho dos produtos, sendo possivel administrar a eficiência de controle com economia e ganho em logística operacional apenas em função da escolha adequada da ponta de pulverização.

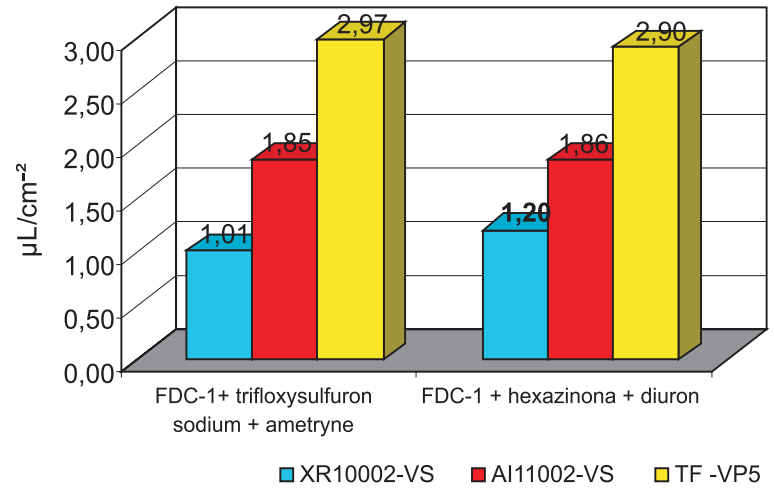

Figura 3 - Volumes médios das soluções de FDC-1 + trifloxysulfuron-sodium + ametryne e FDC-1 + hexazinone+diuron depositadas por unidade de área no solo nas entrelinhas da cultura da cana-de-açúcar, utilizando-se diferentes pontas de pulverização.

\section{LITERATURA CITADA}

BARROS, C. A.; LEONEL, D. M. Eficácia e seletividade da mistura trifloxysulfuron-sodium/ametryne para o controle de plantas daninhas na cultura da cana-de-açúcar. R. Bras. Herbic., v. 2, n. 3, p. 93-97, 2001

COLETI, J. T. et al. Brachiaria pode provocar sérios danos nos canaviais. Inf. Coopercitrus, n. 132, p. 34-35, 1977.

CONSTANTIN, J. et al. Avaliação de períodos de controle das plantas daninhas sobre o crescimento e produtividade da cana-de-açúcar. In: CONGRESSO BRASILEIRO DE HERBICIDAS E PLANTAS DANINHAS, 19., 1993, Londrina. Resumos... Londrina: 1993. p. 50-52.

CONSTANTIN, J. Avaliação da seletividade do herbicida halosulfuron na cultura da cana-de-açúcar (Saccharum spp.). 1996. 71 f. Tese (Doutorado em Agronomia) - Universidade Estadual Paulista, Botucatu, 1996.

DILLEWIJN, C. van. Botany of sugar cane. Waltham: Chronica Botanica, 1952. 371 p.

EUROPEAN WEED RESEARCH COUNCIL - EWRC. Methods in weeds research. Weed Res., v. 4, p. 88, 1964.

FENER, M. Germination tests of thirthy-two East African weed species. Weed Res., v. 20, p. 135-138, 1980.

FNP - CONSULTORIA E COMÉRCIO. AGRIANUAL 2008. Anuário da agricultura brasileira. São Paulo: 2001. p. $235-262$.

Planta Daninha, Viçosa-MG, v. 26, n. 3, p. 665-676, 2008 
GRAVENA, R. et al. Efeito da palha de cana-de-açúcar e de tryfloxysulfuron-sodium + ametrina no controle de plantas daninhas. In: CONGRESSO BRASILEIRO DA CIÊNCIA DAS PLANTAS DANINHAS, 23., 2000, Gramado. Resumos... Londrina: 2002. p. 506.

GRACIANO, P. A. Interferência e manejo de plantas daninhas em áreas de cana-de-açúcar (Saccharum spp.) intercaladas com feijão (Phaseolus vulgaris e Vigna unguiculata L. Walp.). 1989. 184 f. Dissertação (Mestrado em Fitotecnia) - Escola Superior de Agricultura "Luiz de Queiroz", Piracicaba, 1989

KUVA, M. A. et al. Períodos de interferência das plantas daninhas na cultura da cana-de-açúcar. I - Tiririca. Planta Daninha, v. 18 , n. 2, p. 241-251, 2000

KUVA, M. A. et al. Períodos de interferência das plantas daninhas na cultura da cana-de-açúcar. II - Capim-braquiária (Brachiaria decumbens). Panta Daninha, v. 19, n. 3, p. 323-330, 2001

KUVA, M. A. et al. Períodos de interferência das plantas daninhas na cultura da cana-de-açúcar. III - Capim-braquiária (Brachiaria decumbens) e capim-colonião (Brachiaria decumbens). Planta Daninha, v. 21, n. 1, p. 37-44, 2003.

LORENZI, H. Plantas daninhas e seu controle na cultura da cana-de-açúcar. In: SEMINÁRIO DE TECNOLOGIA AGRONỔMICA, 4., 1988, Piracicaba. Anais... São Paulo: 1988. p. $281-301$

LORENZI, H. Efeito da planta da cana no controle de plantas daninhas. In: CONGRESSO BRASILEIRO DE HERBICIDAS E PLANTAS DANINHAS, 19., 1993, Londrina. Resumos... Londrina: 1993. p. 28-29.

MARTINS, D. et al. Emergência em campo de dicotiledôneas infestantes em solo coberto com palha de cana-de-açúcar. Planta Daninha, v. 17, n. 1, p. 151-61, 1999.

NEGRISOLI, E. et al. Efeito da quantidade de palha de canade-açúcar (cv. RB855536) sobre a emergência de plantas de Brachiaria decumbens, Brachiaria plantaginea, Digitaria horizontalis e Panicum maximum. In: CONGRESSO BRASILEIRO DA CIÊNCIA DAS PLANTAS DANINHAS, 23., 2000, Gramado. Resumos... Londrina: 2002. p. 516.

PALADINI, L. A. Metodologia para avaliação da deposição em pulverizações. 2000. $111 \mathrm{f}$. Tese (Doutorado em Agronomia) - Universidade Estadual Paulista Júlio de Mesquita Filho, Botucatu, 2000.
PITELLI, R. A. Interferência de plantas daninhas em culturas agrícolas. Inf. Agropec., v. 11, n. 129, p. 16-27, 1985.

PROCÓPIO, S. O. et al. Manejo de plantas daninhas na cultura da cana-de-açúcar. Viçosa, MG: Universidade Federal de Viçosa, 2003. p. 150.

ROLIM, J. C.; CHRISTOFFOLETI, P. J. Período crítico de competição de plantas daninhas com cana planta de ano. Saccharum APC, v. 5, n. 22, p. 21-26, 1982.

SOARES, J. E.; NEMOTO, L.; HUDETZ, M. Trifloxysulfuron-sodium (CGA 362 622) novo herbicida seletivo para a cultura da cana-de-açúcar. In: CONGRESSO BRASILEIRO DA CIÊNCIA DAS PLANTAS DANINHAS, 22., 2000, Foz do Iguaçu. Resumos... Londrina: 2000. p. 318.

SOCIEDADE BRASILEIRA DA CIÊNCIA DAS PLANTAS DANINHAS - SBCPD. Procedimentos para instalação, avaliação e análise de experimentos com herbicidas. Londrina: 1995. $42 \mathrm{p}$.

SOUZA, R. T. Efeito da eletrização de gotas sobre a variabilidade dos depósitos de pulverização e eficácia do glyphosate no controle de plantas daninhas na cultura da soja. 2002. $69 \mathrm{f}$. Tese (Doutorado em Agronomia) Universidade Estadual Paulista, Botucatu, 2002.

TAYLORSON, R. B.; BORTHWICK, H. A. Light filtration by foliar canopies: significance for light-controlled weed seed germination. Weed Sci., v. 17, n. 1, p. 48-51, 1969.

TERRA, M. A. Seletividade de diclosulam, trifloxysulfuron-sodium e ametryne a variedades de cana-de-açúcar. 2003. 60 f. Dissertação (Mestrado em Agronomia) - Universidade Estadual Paulista, Botucatu, 2003.

VELINI, E. D.; NEGRISOLI, E. Controle de plantas daninhas em cana crua. In: CONGRESSO BRASILEIRO DA CIÊNCIA DAS PLANTAS DANINHAS, 22., 2000, Foz do Iguaçu. Palestra... Foz do Iguaçu: Sociedade Brasileira da Ciência das Plantas Daninhas, 2000. p. 148-164.

VELINI, E. D. Estudos e desenvolvimento de métodos experimentais e amostrais adaptados à matologia. 1995. $250 \mathrm{f}$. Tese (Doutorado em Agronomia) - Universidade Estadual Paulista, Jaboticabal, 1995.

ZIMDAHL, R. L. Fundamentals of weed science. New York: Academic Press, 1993. 450 p. 